\title{
Brasil: $\mathrm{O}$ custo do atraso no equacionamento da questão fiscal*
}

Brazil: The cost of delaying fiscal consolidation

RUBENS PENHA CYSNE

CARLOS THADEU DE F. GOMES**

\begin{abstract}
RESUMO: Na situação atual do Brasil, a relação entre a dívida pública e o PIB se eleva não apenas devido à diferença fortemente positiva entre o juro real e o crescimento do produto, mas também devido a um superávit primário negativo e elevado. Isto posto, o ajuste necessário para trazer a relação dívida líquida/PIB a uma condição de sustentabilidade de longo prazo se torna cada dia mais difícil, em função do crescimento da dívida. Este trabalho explicita a metodologia e calcula, para diferentes cenários, trimestre a trimestre, até o prazo de dois anos e meio contados a partir de junho de 2016, o custo de se atrasar o ajuste fiscal. Tal custo se mede pela redução do déficit primário adicional àquela que precisaria ser feita, caso o ajuste tivesse se dado em meados de 2016. Dependendo do cenário e se a dívida considerada é a bruta ou a líquida, o custo de um ano de atraso pode variar entre $0,14 \%$ e $0,67 \%$ do PIB. O custo anual pode ainda se situar acima de $0,67 \%$ do PIB se, a partir de meados de 2016 , o juro real médio periódico superar $6,6 \%$ ao ano, e/ou o produto crescer abaixo de $-1,6 \%$ ao ano.
\end{abstract}

PALAVRAS-CHAVE: Economia brasileira; ajuste fiscal; déficit fiscal; superávit primário; solvência da dívida; sustentabilidade da dívida.

ABSTRACT: In the present situation, the debt/GDP ratio in Brazil is increasing both due to the payment of interests and to a positive primary deficit. The later the fiscal adjustment is done, the higher must be the reduction of the primary deficit to attain long-run debt sustainability. This work makes the deduction of the cost of delay explicit and uses it to derive some data concerning the present Brazilian case. It considers three different scenarios and a two-and-a-half year period starting in June of 2016. The cost of delaying the adjustment is

\footnotetext{
* Esta é uma versão atualizada do Trabalho preparado por solicitação do Ministro João Paulo dos Reis Velloso, para apresentação em 15/09/2016 no Fórum Nacional. Os autores agradecem, sem implicar nos erros porventura existentes, ao Ministro Ernane Galveas por conversas sobre o tema. E a Gabriel Dias, Gabriel Lima e Layla Mendes pela assistência de pesquisa.

* Rubens Penha Cysne é Professor da FGV/EPGE - Escola Brasileira de Economia e Finanças da Fundação Getulio Vargas. E-mail: rubens.cysne@fgv.br. Carlos Thadeu de Freitas Gomes é Economista Chefe da Confederação Nacional do Comércio (CNC). E-mail: carlosgomes@cnc.org.br. Submetido: 6/11/2016; Aprovado: 6/abril/2017.
} 
measured in terms of the additional reduction of the primary deficit relative to that which would have been necessary had the sustainability condition been met in June of 2016. Depending upon the scenario and on the concept of debt, a one year delay may demand between $0.14 \%$ and $0.67 \%$ of GDP of additional reduction of the primary deficit. The inertia may also lead to more uncomfortable figures, in case the average yearly periodic real interest rate as of June 2016 exceeds $6.6 \%$. Or if average GDP yearly growth is lower than $-1.6 \%$ in the period considered.

KEYWORDS: Brazilian economy; fiscal consolidation; fiscal deficit; primary surplus; debt solvency; debt sustainability.

JEL Classification: E60; E62; E65; H63; H68.

\section{INTRODUÇÃO}

À medida que a dívida cresce em relação ao PIB, maior é o esforço fiscal necessário para reverter sua trajetória, pois a conta de juros aumenta e é agravada pelo aumento dos prêmios de risco. O saldo primário necessário para estabilizar o crescimento da dívida pública é cada vez maior.

Este trabalho tem por objetivo avaliar quantitativamente, sob diferentes cenários, o custo de se postergar o ajuste fiscal no Brasil tomando como base junho de 2016.

O conceito de setor público utilizado é aquele de governo geral (esferas federal, estadual e municipal, não incluindo o Banco Central). Dada a possível heterogeneidade entre ativos e passivos públicos, os cálculos são todos efetuados considerando-se a dívida líquida e a dívida bruta.

São apresentados, com relação à dívida pública:

i) suas condições de sustentabilidade de longo prazo; e

ii) o custo trimestral de se postergar o ajuste fiscal.

$\mathrm{O}$ custo a que se refere o item (ii) mensura o esforço fiscal adicional (medido em termos de redução do déficit primário) para atender à condição de sustentabilidade da dívida, relativamente àquele que teria sido necessário caso o ajuste (à condição de sustentabilidade) tivesse se dado em junho de 2016.

O modelo de equilíbrio parcial e de curto prazo (consideramos apenas dois anos e meio contados a partir de determinada data) aqui utilizado não estabelece assimetria, no cálculo do custo do atraso no equacionamento da questão fiscal, entre aumento de receitas primárias e redução de gastos. A inflação, os juros e a taxa de crescimento do PIB, que seriam parâmetros certamente sensíveis a estas duas alternativas, são exogenamente estabelecidos nos cálculos através de diferentes cenários.

Isto posto, o esforço fiscal pode se medir aqui sempre diretamente em termos da redução requerida do déficit primário (ou aumento do superávit primário), sem levar em conta a alternativa entre elevação de impostos ou redução de despesas. Não é objetivo dos autores discutir, neste trabalho, a assimetria gerada por estas alternativas. 


\section{MODELO}

Como o trabalho tem um objetivo bastante preciso, abstraímo-nos aqui de comentar a vasta literatura atual concernente à restruturação das contas públicas.

Seguimos o modelo básico de evolução da dívida líquida pública em equilíbrio parcial. A equação básica de evolução da dívida líquida do governo $B$ é tautologicamente dada por:

$$
\dot{B}=i B+G+H-T
$$

onde $i$ representa a taxa de juros nominal, $G$ os gastos de consumo e investimento do governo, $H$ as transferências e $T$ as receitas primárias (receitas tributárias mais outras receitas correntes líquidas). Admite-se aqui, em opção metodológica, que $i$ seja a taxa bruta sobre a dívida pública (portanto não deduzindo o que volta para o governo sob a forma de impostos sobre os juros) e que, consistentemente, tais impostos se incluam na variável $T$. A opção alternativa, de considerar $i$ como taxa líquida e não incluir os impostos sobre os juros da dívida pública em $T$, em nada modificaria os resultados do trabalho.

Fazendo $X$ representar $B, G, H$ ou $T$, defina a contrapartida minúscula $x$ como sua fração em relação ao PIB nominal $(x=X / P Y)$, onde $P$ representa o índice de preços e $Y$ o PIB real. Adicionalmente, faça $\dot{X}$ representar sua derivada em relação ao tempo. Dividindo ambos os membros de (1) por $P Y$ e usando a fórmula de derivação de uma fração, temos a conhecida equação de evolução da razão dívida/ PIB:

$$
\dot{b}=(r-\theta) b+g+h-t
$$

Em (2), $r$ representa a taxa real de juros instantânea $(r=i-\pi$, sendo $\pi$ a taxa de inflação) e $\theta$ a taxa de crescimento do PIB real. Ao longo deste trabalho, assumiremos sempre que $r-\theta$ seja positivo e constante. Neste caso, a equação diferencial não homogênea (2) pode ser facilmente resolvida utilizando-se o fator de integração $e^{-(r-\theta) u}$. Temos então, fazendo $n$ representar um número real que denota tempo:

$$
b_{n}=b_{0} e^{(r-\theta) n}+\int_{0}^{n}\left(g_{s}+h_{s}-t_{s}\right) e^{(r-\theta)(n-s)} d s
$$

Ou seja, em moeda do instante $n$, a razão dívida/PIB no período $n$ é dada pelo montante atualizado (sempre à taxa $r-\theta$ ) da dívida no instante zero, mais o somatório dos déficits primários entre o instante zero e o instante $n$, capitalizados à taxa $(r-\theta)$. A mesma equação pode ser escrita em moeda de poder aquisitivo do instante zero, bastando para isto multiplicar ambos os membros por $e^{-(r-\theta) n}$. Nesse caso:

$$
b_{n} e^{-(r-\theta) n}=b_{0}+\int_{0}^{n}\left(g_{s}+h_{s}-t_{s}\right) e^{-(r-\theta) s} d s
$$




\section{Condição de Sustentabilidade}

Considera-se aqui a usual condição de sustentabilidade da dívida no longo prazo:

$$
\lim _{n \rightarrow \infty} b_{n} e^{-(r-\theta) n} \leq 0
$$

Usando (5) em (4) obtemos a condição usual de um governo solvente: o valor atual dos déficits primários deve ser inferior aos ativos líquidos de posse do governo no instante zero $\left(-b_{0}\right)$ :

$$
-b_{0} \geq \int_{0}^{\infty}\left(g_{s}+h_{s}-t_{s}\right) e^{-(r-\theta) s} d s
$$

No restante deste trabalho usaremos (5) e (6) sob forma de igualdade. A hipótese implícita é que os contribuintes pressionem o governo a não manter ativos líquidos ao final do seu horizonte de planejamento.

\section{Receita Primária Constante}

\section{Sustentabilidade}

Como observam Blanchard (1990) e Blanchard et al. (1990), uma pergunta interessante decorrente do critério de solvência acima, dadas as trajetórias temporais dos gastos $g$ e das transferências $h$, bem como os valores predeterminados de $b_{0}$ e $(r-\theta)$, diz respeito ao nível constante de receitas que assegure ao governo uma trajetória de sustentabilidade a partir do instante zero. Denotamos tal nível de receitas por $t_{\infty}^{*}(0) \cdot t_{\infty}^{*}(0)$ pode ser facilmente obtido de (6), bastando para isto notar que para $t$ constante $\int_{0}^{\infty} t_{\infty}^{*}(0) e^{-(r-\theta) s} d s=t_{\infty}^{*}(0) /(r-\theta)$. Tem-se então:

$$
t_{\infty}^{*}(0)=(r-\theta)\left[b_{0}+\int_{0}^{\infty}\left(g_{s}+h_{s}\right) e^{-(r-\theta) s} d s\right]
$$

$\mathrm{Ou}$, equivalentemente:

$$
\frac{t_{\infty}^{*}(0)}{(r-\theta)}=\int_{0}^{\infty}\left(g_{s}+h_{s}+(r-\theta) b_{0}\right) e^{-(r-\theta) s} d s
$$

A equação (8) informa que, em moeda do instante zero, o valor atual da receita primária (taxação mais outras receitas correntes líquidas) constante deve ser suficiente, como fração do PIB, para igualar o valor atual da trajetória futura dos gastos de consumo e investimento $(g)$; de transferências $(h)$; e o juro real, descontado pela taxa de crescimento do produto, incidente sobre a dívida $\left((r-\theta) b_{0}\right)$. Todos estes, também, 
como fração do PIB. E descontados para o instante zero pela diferença entre o juro real e a taxa de crescimento do produto ${ }^{1}$.

Interpretação Alternativa para $\left(t_{\infty}^{*}(0)\right)$ :

Uma pergunta interessante nesta análise determinística de equilíbrio parcial diz respeito ao cálculo de uma taxação constante para se trazer a relação dívida / PIB ao montante original (relativo ao período zero) ao final de $n$ períodos. Definimos tal taxação por $\hat{t}_{n}(0)$. Tem-se aqui um a notação $\hat{t}$ ao invés da notação $t^{*}$ anterior em função da interpretação alternativa.

No caso anterior, referimo-nos a uma taxação constante para atender à condição de sustentabilidade. Aqui, referimo-nos a uma taxação constante que traga a razão dívida/PIB de volta ao seu valor original. Fazendo-se $t$ constante e $b_{0}=b_{n}$ em (4) obtém-se facilmente, mediante integração:

$$
\hat{t}_{n}(0)=(r-\theta)\left[b_{0}+\left(1-e^{-(r-\theta) n}\right)^{-1} \int_{0}^{n}\left(g_{s}+h_{s}\right) e^{-(r-\theta) s} d s\right]
$$

A fórmula acima nos mostra que $\hat{t}_{n}(0)$ deve ser suficiente para cobrir duas parcelas. Primeiro, o montante $(r-\theta) b_{0}$ que mantém constante a razão dívida/PIB na ausência de despesas primárias. Segundo, uma média ponderada das despesas primárias entre os tempos 0 e $n$. De fato, observe que os pesos que ponderam $\left(g_{s}+h_{s}\right)$ em (10), no intervalo de tempo considerado, somam 1.

Introduzindo a definição $\hat{t}_{\infty}(0):=\lim _{n \rightarrow \infty} \hat{t}_{n}(0)$ e tomando-se limites em (10):

$$
\hat{t}_{\infty}(0):=\lim _{n \rightarrow \infty} \hat{t}_{n}(0)=t_{\infty}^{*}(0)
$$

Ou seja, a receita primária constante que traz razão dívida/PIB de volta ao seu valor original ao final de $n$ períodos coincide, quando $n$ tende a infinito, com a receita primária constante que atende à condição de sustentabilidade (5) sob a forma de igualdade.

\section{Condição de Sustentabilidade Instantânea $\left(\hat{t}_{0}(0)\right)$ :}

Pela definição aqui usada, $\hat{t}_{0}(0)$ representa a receita primária constante a partir do momento zero que mantém constante a razão dívida/PIB existente no instante zero. Segue diretamente de (2) que:

${ }^{1}$ Cabe notar que o mesmo tipo de procedimento pode ser feito em relação às despesas, tomando-se a taxação ao longo do tempo como dada. Neste caso, a contrapartida de (8) é dada por:

$$
\frac{(g+h)_{\infty}^{*}(0)}{(r-\theta)}=\int_{0}^{\infty}\left(t_{s}-(r-\theta) b_{0}\right) e^{-(r-\theta) s} d s \quad(9)
$$

A equação (9) informa que, em moeda do instante zero e como fração do PIB, o valor atual dos gastos públicos (supostos aqui constantes) deve se igualar ao valor atual da carga tributária, porém líquida do pagamento de juros reais sobre o valor inicial da dívida líquida. 


$$
\hat{t}_{0}(0)=b_{0}(r-\theta)+(g+h)_{0}
$$

Ou seja, a condição de sustentabilidade instantânea determina que a carga tributária seja, no ponto inicial de análise, coincidente com a soma das despesas totais do governo incluindo o juro real (neste trabalho, sempre corrigido pelo crescimento do produto) sobre a dívida.

Tomando-se agora em (10) o limite quando $n \rightarrow 0$ obtém-se, usando-se L'Hôspital:

$$
\lim _{n \rightarrow 0} \hat{t}_{n}(0)=\hat{t}_{0}(0)
$$

\section{g+h constante:}

Integrando-se (7) sob a hipótese de se ter também $g+b$ constante, obtém-se facilmente:

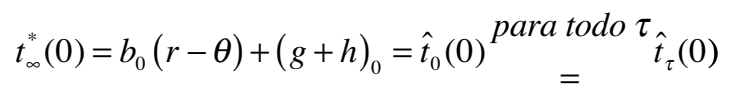

\section{DADOS UTILIZADOS}

Os dados aqui utilizados provêm do Banco Central, do IBGE, do Tesouro Nacional e do Sistema de Informações Contábeis e Fiscais do Setor Público Brasileiro (Siconfi, atrelado à Secretaria do Tesouro Nacional).

As receitas primárias foram computadas por meio da adição das receitas primárias de estados e municípios às receitas primárias do governo federal. As últimas foram obtidas do Tesouro Nacional (cabe destacar que foi utilizada a "Estrutura Nova"), enquanto as receitas primárias dos governos estaduais e municipais foram obtidas no Siconfi. Chega-se ao valor dos gastos primários somando-se às receitas primárias o déficit primário do governo geral.

Os desenvolvimentos formais na segunda seção, como deixa claro a equação (1), referem-se todos à dívida líquida do governo. Seguindo uma tendência recente no estudo da questão fiscal brasileira, entretanto, todos os resultados apresentados neste trabalho utilizam também dados relativos à dívida bruta do setor público.

A utilização da dívida bruta pressupõe a desconsideração dos ativos do governo geral, bem como a sua remuneração. Trata-se de hipótese certamente muito forte. Na prática, ela faz com que a equação (1) tenha que ser interpretada apenas como uma aproximação, já que ao déficit nominal não se contrapõe variação de igual valor da dívida bruta. Isto ocorre apenas com a dívida líquida.

Por outro lado, trabalhar-se apenas com o conceito de dívida líquida requer que a qualidade e remuneração dos ativos do governo não difira muito daquelas associadas ao seu passivo, hipótese também questionável por alguns estudos fiscais recentes.

Optamos então por apresentar sempre os resultados tomando como ponto de 
partida ambos os conceitos de dívida. Com base nestes, o leitor poderá tomar a média ponderada dos mesmos que achar a mais adequada.

Relativamente a junho de 2016, os dados do Banco Central apontam uma dívida líquida do governo geral de $43,4 \%$ do PIB, e uma dívida bruta de $68,5 \%$ do PIB. Para os gastos do governo como percentual do PIB, incluindo transferências $((\mathrm{g}+\mathrm{h}) * 100)$, utilizaremos $38,03 \%$ (o valor nas tabelas abaixo está aproximado para duas casas decimais). Tal percentual é obtido somando-se às receitas primárias (trabalhamos aqui com $35,46 \%^{2}$ do PIB) o déficit primário esperado para 2016 (2,57\% do PIB). Como nosso ponto de partida é junho de 2016, tal aproximação equivale a supor determinada estabilidade desses parâmetros a partir de junho de 2015. Trata-se esta de hipótese anódina, em particular, quando se considera o regime contábil de competência.

\section{Cenários:}

Para efeito de evolução futura do crescimento do PIB real, inflação e juros, utilizaremos quatro cenários para a dívida. Os cenários são construídos tendo como base dois anos e meio contados a partir de julho de 2016. O cenário 4 talvez seja mais adequado para um período menor (um ano a partir de junho de 2016, por exemplo), tendo em vista que não se espera que o PIB real cresça $-1,6 \%$ ao ano durante dois anos e meio.

Com base nas derivações aqui apresentadas, o leitor pode introduzir o cenário alternativo que julgar o mais adequado.

Tabela 1: Cenários Utilizados

\begin{tabular}{|c|c|c|c|c|}
\hline & Juro Nom. Efetivo & Infla. & Cresc. Prod. & $(g+h)_{0}$ \\
\hline Cenário 1 & 12,5 & 6,0 & 2,6 & 0,38 \\
\hline Cenário 2 & 13,5 & 6,5 & 2,1 & 0,38 \\
\hline Cenário 3 & 14,0 & 7,0 & 1,6 & 0,38 \\
\hline Cenário 4 & 13,0 & 6,0 & $-1,6$ & 0,38 \\
\hline
\end{tabular}

As taxas acima - juro nominal efetivo, inflação (Infla) e crescimento do produto (Cresc. Prod.) - são periódicas e anualizadas. Sua utilização nas fórmulas

\footnotetext{
${ }^{2} \mathrm{O}$ valor referente à receita primária do governo geral pode ser calculado somando-se à carga tributária de 32,66\% do PIB, divulgada pela Receita Federal ("Carga Tributária no Brasil, 2015"), as outras receitas correntes líquidas. São estas: Concessões $(0,3 \%$ do PIB), Royalties $(0,4 \%)$, Receitas Próprias $(0,2 \%)$, Complemento do FGTS $(0,1 \%)$ e Dividendos $(0,2 \%)$ - em nível federal - e Receitas Patrimoniais e de Capital Primárias (1\%) - em níveis estadual e municipal. Incluindo-se as demais receitas, chega-se a um total de $2,8 \%$ do PIB. Daí, obtém-se, por soma, a receita primária do governo geral utilizada: $35,46 \%$ do PIB.
} 
deduzidas na segunda seção demanda a passagem para taxas logarítmicas (que podem ser somadas ou subtraídas sem que isso represente aproximações).

\section{ÍNDICE DE SUSTENTABILIDADE DA DÍVIDA}

Dado exogenamente o valor da carga tributária no instante $0, t(0)$, pode-se definir o índice de sustentabilidade da dívida, no instante, como:

$$
S(0)=t_{\infty}^{*}(0)-t(0)
$$

Trata-se de quanto se deve elevar (de forma constante no tempo) as receitas primárias, no instante inicial, de forma a se ter satisfeita a condição de sustentabilidade (6) (sob forma de igualdade).

Observe de (8) que o cálculo de $t_{\infty}^{*}(0)$ exige o conhecimento de toda a trajetória futura de $g+h$. Como não dispomos de previsões sobre tal variável, assumiremos nesta seção, para cálculo de $S(0)$, que $g+h$ seja constante no tempo. Pelo que vimos na segunda seção, neste caso podemos fazer $t_{\infty}^{*}(0)=\hat{t}_{0}(0)$. Como vimos antes, $\hat{t}_{0}(0)$ calcula-se então facilmente a partir de (12).

Para os quatro cenários anteriores, apresentamos na Tabela 2 os valores do índice de sustentabilidade.

Os números entre parênteses denotam os cálculos relativos à dívida bruta:

Tabela 2: Índice de Sustentabilidade (\% do PIB)

\begin{tabular}{|c|c|}
\hline & $S(0)$ \\
\hline Cenário 1 & $4,03(4,88)$ \\
\hline Cenário 2 & $4,43(5,50)$ \\
\hline Cenário 3 & $4,63(5,82)$ \\
\hline Cenário 4 & $6,04(8,05)$ \\
\hline
\end{tabular}

No caso da dívida líquida, por exemplo, o atendimento à condição de sustentabilidade sob as hipóteses efetuadas acima exigiria reduções do déficit primário de, respectivamente, 4,03\%; 4,43\%; 4,63\% e 6,04\% do PIB, nos cenários 1, 2, 3 e 4 . No cenário 2, por exemplo, a manutenção das receitas primárias em 35,46\% do PIB exigiria uma queda das despesas primárias de $38,03 \%$ para $33,6((38,03-$ $4,43) \%$ do PIB).

No caso de despesas constantes e redução do déficit primário apenas com base na elevação de impostos, é importante observar que tal elevação incide não sobre o PIB como um todo, mas sobre a parcela ainda não apropriada pelo governo. Isto implica maior esforço fiscal. Como sugerem Blanchard (1990) e Blanchard et al. (1990), um indicador efetivo esforço fiscal neste caso $\left(S_{E}\right)$ pode ser dado por:

$$
S_{E}(0)=\frac{\hat{t}_{0}(0)-t(0)}{1-t(0)}
$$


Considerando ainda a dívida líquida como a representativa do governo e o cenário 2 , isto significa uma transferência para o governo de $4,43 \%$ sobre um total de $64,54 \%$ do PIB ainda não apropriado pelo mesmo. Ou seja, o esforço fiscal efetivo pode ser medido por $S_{E}$; que no caso implica transferência efetiva de $6,86 \%$ da renda disponível do setor privado.

Em qualquer cenário ou escolha do tipo de dívida e de indicador (se $S(0)$ ou $S_{E}(0)$ ), os valores de redução do déficit primário são bastante elevados. Isto implica dizer que não há alternativa socialmente viável no curto prazo que não inclua elevação, por algum tempo, da razão dívida/PIB. Isso nos leva ao ponto principal deste trabalho, o cálculo do custo do atraso na solução do problema fiscal.

\section{O CUSTO DO ATRASO}

Para o claro entendimento do que definimos aqui como custo do atraso, tomemos, a título de exemplo, os $4,43 \%$ do PIB a que faz menção o cenário 2 da Tabela 2. Este número corresponde a quanto se deveria reduzir o déficit primário em junho de 2016, sob as hipóteses até aqui efetuadas, para se atender à condição de sustentabilidade da dívida. Pode-se aqui pensar, como vimos na segunda seção, tanto na condição de sustentabilidade de longo prazo, em um cenário de $t$ e $g+h$ constantes, como na condição de sustentabilidade instantânea.

Suponha agora que este tipo de ajuste não se dê no ponto do tempo considerado (junho de 2016), mas sim em um espaço de tempo $\tau$ contado a partir desta data. Ao se postergar o ajuste fiscal de um montante de tempo $\tau>0$, a dívida/PIB terá aumentado de $b_{0}$ para $b_{\tau}$. Isto implicará maior pagamento de juros e, consequentemente, um maior esforço fiscal a ser feito para atender à condição de sustentabilidade do tempo $\tau$ para a frente. O novo superávit primário implicado pela condição de sustentabilidade da dívida no cenário 2 será, portanto, superior aos $4,43 \%$ do PIB relativos ao tempo zero (aqui, junho de 2016).

À contrapartida do indicador $t_{\infty}^{*}(0)$ definido anteriormente, mas agora assumindo a princípio uma carga tributária constante a partir do instante $\tau$ e não mais a partir do instante 0 , damos aqui a designação de $t_{\infty}^{*}(\tau)$.

Define-se então o Custo do Atraso como:

$$
C(\tau)=t_{\infty}^{*}(\tau)-t_{\infty}^{*}(0)
$$

onde $t_{\infty}^{*}(0)$ é dado por (7). Observe que se trata de uma diferença entre a receita primária que garante a condição de sustentabilidade no caso em que o ajuste no tempo $\tau>0$ e aquela que teria sido necessária para satisfazer à mesma condição, tivesse o ajuste sido feito no tempo 0 . Em outras palavras, $C(\tau)$ mede o custo de se postergar o ajuste fiscal por um tempo $\tau$ sendo tal ajuste fiscal perfeitamente definido a partir das definições de $t_{\infty}^{*}(\tau)$ e $t_{\infty}^{*}(0)$.

Calcularemos aqui $C(\tau)$ trimestre a trimestre, para os diferentes cenários con- 
siderados e para os dois conceitos de dívida utilizados, até o prazo máximo de dois anos e meio a partir de junho de 2016.

\section{Dedução de $C(\tau)$}

A equação (22) aparece em Blanchard et al. (1990), porém desacompanhada da respectiva dedução. Uma aproximação da mesma, também sem se acompanhar da dedução, aparece em Blanchard (1990). A dedução apresentada nesta subseção é própria dos autores.

Reescrevendo (7) para o tempo $\tau>0$, temos:

$$
t_{\infty}^{*}(\tau)=(r-\theta)\left[b_{\tau}+\int_{\tau}^{\infty}\left(g_{s}+h_{s}\right) e^{-(r-\theta)(s-\tau)} d s\right]
$$

Trazendo para moeda do instante zero:

$$
t_{\infty}^{*}(\tau) e^{-(r-\theta) \tau}=(r-\theta)\left[b_{\tau} e^{-(r-\theta) \tau}+\int_{\tau}^{\infty}\left(g_{s}+h_{s}\right) e^{-(r-\theta) s} d s\right]
$$

De (7) e (17):

$$
t_{\infty}^{*}(\tau) e^{-(r-\theta) \tau}-t_{\infty}^{*}(0)=(r-\theta)\left[b_{\tau} e^{-(r-\theta) \tau}-b_{0}+\int_{0}^{\tau}-\left(g_{s}+h_{s}\right) e^{-(r-\theta) s} d s\right]
$$

Usando (4):

$$
t_{\infty}^{*}(\tau) e^{-(r-\theta) \tau}-t_{\infty}^{*}(0)=(r-\theta) \int_{0}^{\tau}-t e^{-(r-\theta) s} d s
$$

Para valores de $\tau$ suficientemente pequenos assumimos $t$ como constante entre os tempos 0 e $\tau$. Neste caso, mediante integração, fazendo arbitrariamente $t=t(0)$ :

$$
t_{\infty}^{*}(\tau) e^{-(r-\theta) \tau}-t_{\infty}^{*}(0)=t(0)\left(-1+e^{-(r-\theta) \tau}\right)
$$

Somando-se $-t_{\infty}^{*}(0) e^{-(r-\theta) \tau}$ a ambos os termos de $(20)$ :

$$
\left[t_{\infty}^{*}(\tau)-t_{\infty}^{*}(0)\right] e^{-(r-\theta) \tau}=\left(t(0)-t_{\infty}^{*}(0)\right)\left(-1+e^{-(r-\theta) \tau}\right)
$$

Donde se obtém imediatamente, multiplicando-se ambos os termos de (21) por $e^{(r-\theta) \tau}$ :

$$
C(\tau)=t_{\infty}^{*}(\tau)-t_{\infty}^{*}(0)=\left(-1+e^{(r-\theta) \tau}\right)\left(t_{\infty}^{*}(0)-t(0)\right)
$$

Observe que o cálculo de $S(0):=t_{\infty}^{*}(0)-t(0)$ feito na seção anterior aproxima $t_{\infty}^{*}(0)$ por $\hat{t}_{0}(0)$. A dedução aqui apresentada de $C(\tau)$, entretanto, prescinde desta hipótese. 


\section{Custo do Atraso Escrito em Função da Elevação da Razão Dívida/PIB}

Para uma visão alternativa do significado de (22), é interessante avaliar como evolui a razão dívida/PIB sob as hipóteses aqui efetuadas. Para isto, observe que, de (4) (com $\tau$ no lugar de $n$ ):

$$
\left(b_{\tau}-b_{0}\right) e^{-(r-\theta) \tau}=b_{0}\left(1-e^{-(r-\theta) \tau}\right)+\int_{0}^{\tau}\left(g_{s}+h_{s}-t_{s}\right) e^{-(r-\theta) s} d s
$$

É interessante escrever $\int_{0}^{\tau}\left(g_{s}+h_{s}\right) e^{-(-1-\theta) s} d s$ em função da taxação constante que traz a relação dívida-PIB de volta ao seu valor inicial ao final do tempo $\tau\left(\hat{t}_{\tau}(0)\right)$. Para isto, pode-se usar (23) fazendo-se $b_{\tau}-b_{0}=0$ :

$$
\int_{0}^{\tau}\left(g_{s}+h_{s}\right) e^{-(r-\theta) s} d s=\left(\frac{\hat{t}_{\tau}(0)}{r-\theta}-b_{0}\right)\left(1-e^{-(r-\theta) \tau}\right)
$$

Admitamos agora que a taxação inicial $t(0)$, qualquer que seja, permaneça constante entre os tempos zero e $\tau$. Neste caso

$$
\int_{0}^{\tau}-t(0) e^{-(r-\theta)} d s=\frac{-t(0)}{(r-\theta)}\left(1-e^{-(r-\theta) \tau}\right)
$$

Usando-se (23), (24) e (25) tem-se:

$$
\begin{aligned}
& \left(b_{\tau}-b_{0}\right) e^{-(r-\theta) \tau}=\frac{\hat{t}_{\tau}(0)-t(0)}{(r-\theta)}\left(1-e^{-(r-\theta) \tau}\right) \\
& b_{\tau}-b_{0}=\frac{\hat{t}_{\tau}(0)-t(0)}{(r-\theta)}\left(e^{(r-\theta) \tau}-1\right)
\end{aligned}
$$

Em (26), o membro do lado direito exprime a diferença da razão dívida/PIB entre os instantes 0 e $\tau$. O membro do lado direito expressa esta diferença em termos da diferença entre a receita primária constante que traz a razão dívida/PIB ao seu valor original, no tempo $\tau\left(\hat{t}_{\tau}(0)\right)$, e a taxação existente no momento inicial, $t(0)$, se mantida constante até o tempo $\tau$.

\section{Cálculo do Custo do Atraso}

Para o cálculo efetivo de $S(0)$ na quarta seção, aproximamos $t_{\infty}^{*}(0)$ por $\hat{t}_{0}(0)$. Uma condição suficiente para que isto se dê é que $g+h$, além de t, seja também constante no tempo. Observe que não precisamos de tal hipótese para a dedução nem de (22) nem de (26).

Mas, tal como na quarta seção, por falta de previsibilidade da função $g(t)+h(t)$, assumimos nas avaliações empíricas aqui efetuadas que tal valor se iguale, para 
todo tempo $t$, ao valor existente no instante zero. Neste caso, tem-se $\hat{t}_{\tau}(0)=t_{\infty}^{*}(0)=\hat{t}_{0}(0)$. Usando tal fato em $(26)$ :

$$
b_{\tau}-b_{0}=\frac{t_{\infty}^{*}(0)-t(0)}{(r-\theta)}\left(e^{(r-\theta) \tau}-1\right)
$$

Observe que, sob as hipóteses efetuadas, (27) nos permite agora expressar o custo do atraso em função da elevação de dívida entre os instantes zero e $\tau$ como:

$$
C(\tau)=(r-\theta)\left(b_{\tau}-b_{0}\right)
$$

Vejamos alguns exemplos colocados sob este prisma.

Tome o cenário 2, no qual a condição de sustentabilidade da dívida implica, como mostra a Tabela 2, uma elevação de $S(0)=4,43 \%$ (cenário 2, dívida líquida) do PIB do superávit primário do governo. Considere o prazo de um ano, ou seja, tome $\tau=1 \mathrm{em}$ (22). Observe que estamos tratando com taxas logarítmicas, e as taxas apresentadas nos diferentes cenários são periódicas. Temos então $\left(e^{(r-\theta) \tau}-1\right)=-1+\frac{1,135}{1,065 * 1,021}=0,0438$. Como $(r-\theta)=\ln \left(\frac{1,135}{1,065 * 1,021}\right)=0,0429$, temos $\left(\frac{e^{(r-\theta) \tau}-1}{(r-\theta)}\right)=1,0216$. Isto implica por (27) que $b_{\tau}-b_{0}=1,0216 * 4,43 \%=4,5257 \%$ do PIB. O custo de se atrasar o ajuste em um ano é dado então por $0,0429 * 4,5257 \%=0,19 \%$ do PIB.

Uma forma alternativa de visualizar o cálculo de $C(\tau)$ se dá através do uso direto de (22). Tem-se então $\left(e^{(r-\theta) \tau}-1\right)=0,0438 \mathrm{e}$, aproximando-se $t_{\infty}^{*}(0)$ por $\hat{t}(0)$, $C(\tau)=\left(-1+e^{(r-\theta) \tau}\right) S(0)=0,0438 * 4,43 \%=0,19 \%$ do PIB, tal como no cálculo anterior.

Aproximações à parte, este é o número que se lê no caso da dívida líquida na Tabela 3, no cenário 2 , trimestre 4 .

Se tivéssemos considerado a dívida bruta, ao invés da líquida, a lógica do cálculo seria a mesma, bastando trocar $4,43 \%$ do PIB por $5,50 \%$ do PIB (número no cenário 2 da Tabela 2 entre parênteses). Usando (28) ao invés de (2), o aumento da razão dívida/PIB neste caso seria de $1,0216 * 5,50 \%=5,619 \%$. O custo do atraso de um ano é então dado 0,0429*5,5619\% = 0,241\% do PIB, que corresponde ao número 0,24 apresentado na posição relativa ao trimestre 4 , cenário 2 na Tabela $3^{3}$.

\footnotetext{
${ }^{3}$ Os dados efetivos de evolução da razão dívida/PIB de junho a dezembro, disponíveis quando da revisão final deste trabalho, deixam claro o problema gerado pela utilização das fórmulas deduzidas na segunda seção com o conceito de dívida bruta, ao invés de líquida. Referimo-nos a este ponto na terceira seção deste trabalho.

De junho a dezembro de 2016 (seis meses), a dívida líquida do governo geral se elevou efetivamente em $4,60 \%$ do PIB, número compatível com os $4,525 \%$ do PIB anuais aqui calculados. Isto, a despeito de se tratar tal cálculo de uma simples aproximação da realidade por um dos cenários previstos a partir de junho de 2016 - no caso, o de número 2.

A elevação semestral efetiva envolvendo a razão dívida bruta/PIB, por outro lado, foi de apenas $2 \%$ do PIB, número bastante inferior ao que se esperaria a partir dos 5,619\% anuais aqui deduzidos. Parte dessa diferença se explica em função da utilização, pelo governo, entre junho e dezembro de 2016, de uma parcela dos ativos para abater parte da dívida bruta.
} 
A seguir, os resultados para $C(\tau)$ obtidos com base nos 4 cenários apresentados anteriormente. Como antes, os números entre parênteses referem-se à dívida bruta:

Tabela 3: Custo do Atraso

\begin{tabular}{|c|c|c|c|c|}
\hline Trimestre & Cen.1 & Cen.2 & Cen.3 & Cen.4 \\
\hline 1 & $0,03(0,04)$ & $0,05(0,06)$ & $0,06(0,07)$ & $0,12(0,16)$ \\
\hline 2 & $0,07(0,08)$ & $0,10(0,12)$ & $0,11(0,14)$ & $0,25(0,33)$ \\
\hline 3 & $0,10(0,13)$ & $0,14(0,18)$ & $0,17(0,21)$ & $0,37(0,50)$ \\
\hline 4 & $0,14(0,17)$ & $0,19(0,24)$ & $0,23(0,28)$ & $0,50(0,67)$ \\
\hline 5 & $0,17(0,21)$ & $0,24(0,30)$ & $0,28(0,36)$ & $0,64(0,85)$ \\
\hline 6 & $0,21(0,25)$ & $0,29(0,37)$ & $0,34(0,43)$ & $0,77(1,03)$ \\
\hline 7 & $0,25(0,30)$ & $0,34(0,43)$ & $0,40(0,50)$ & $0,91(1,21)$ \\
\hline 8 & $0,28(0,34)$ & $0,40(0,49)$ & $0,46(0,58)$ & $1,05(1,40)$ \\
\hline 9 & $0,32(0,39)$ & $0,45(0,56)$ & $0,52(0,66)$ & $1,19(1,59)$ \\
\hline 10 & $0,36(0,43)$ & $0,50(0,62)$ & $0,58(0,73)$ & $1,34(1,78)$ \\
\hline
\end{tabular}

A Tabela 3 nos permite analisar vários casos.

Tome-se algo em torno de dois anos e meio, contados a partir de junho de 2016. Isto nos coloca em junho de 2018 (trimestre 10 da Tabela 3). O valor de $(\tau)$ no cenário 2 é igual a $0,50 \%$ do PIB quando se considera a dívida líquida. Trata-se, aproximadamente, da metade da arrecadação de um ano de CPMF, se mantidos os parâmetros de quando este imposto foi extinto, em $2007^{4}$.

Consideremos agora a dívida bruta. Como vimos, pela Tabela 2 , considerando também o cenário 2, o superávit primário deveria sofrer um ajuste de 5,50\% para satisfazer à condição de sustentabilidade, da forma como definida na segunda seção. $\mathrm{Na}$ ausência do ajuste, começa a incidir o custo do atraso.

Tomemos os cinco trimestres que vão de junho de 2016 a outubro de 2017. O superávit primário para satisfazer à condição de sustentabilidade passa de 5,5\% para $5,8 \%$ do PIB. A diferença de $0,30 \%$ do PIB representa o Custo de Atraso no equacionamento da questão fiscal (como se lê entre parênteses no trimestre 5, cenário 2 da Tabela 3, já que neste exemplo se considera a dívida bruta).

O pior cenário assumido na Tabela 1 (cenário 4) considera um juro real periódico anual de $6,60 \%$ e crescimento do produto de $-1,6 \%$. Neste caso, o custo do atraso de um ano a partir de junho de 2016 é de $0,50 \%$ do PIB, quando se considera a dívida líquida. E de $0,67 \%$ do PIB quando se considera a dívida bruta.

Como mencionamos na introdução, custo anual pode ainda se situar acima de

\footnotetext{
${ }^{4}$ Em 2007, a arrecadação do CPMF, com alíquota de 0,38\%, era de 1,34\% do PIB; e a do IOF, em torno de $0,3 \%$ do PIB, totalizando $1,64 \%$ do PIB. Com a extinção da CPMF, o novo valor do IOF passou a algo em torno de $0,65 \%$ do PIB. Ou seja, em termos líquidos, a extinção da CPMF correspondeu a algo em torno de $1 \%$ do PIB, valor que usamos aqui.
} 
0,67\% do PIB se, a partir de meados de 2016, o juro real médio periódico superar $6,6 \%$ ao ano, e/ou o produto crescer em média abaixo de $-1,6 \%$ ao ano. O leitor não terá dificuldade em calcular os novos valores do Custo do Atraso neste caso, a partir das fórmulas e exemplos apresentados.

Dependendo da opção pelo cenário e tipo de dívida, a Tabela 3 permite ao leitor a obtenção de oito diferentes números para o Custo de Atraso para cada trimestre, para um total de dez trimestres consecutivos.

Os Gráficos 1-4 abaixo oferecem uma visualização mais geral do Custo do Atraso, assumindo que os valores relativos a cada cenário se mantenham até junho de 2019 (12 trimestres).

\section{Gráficos 1-4: Custo do Atraso}
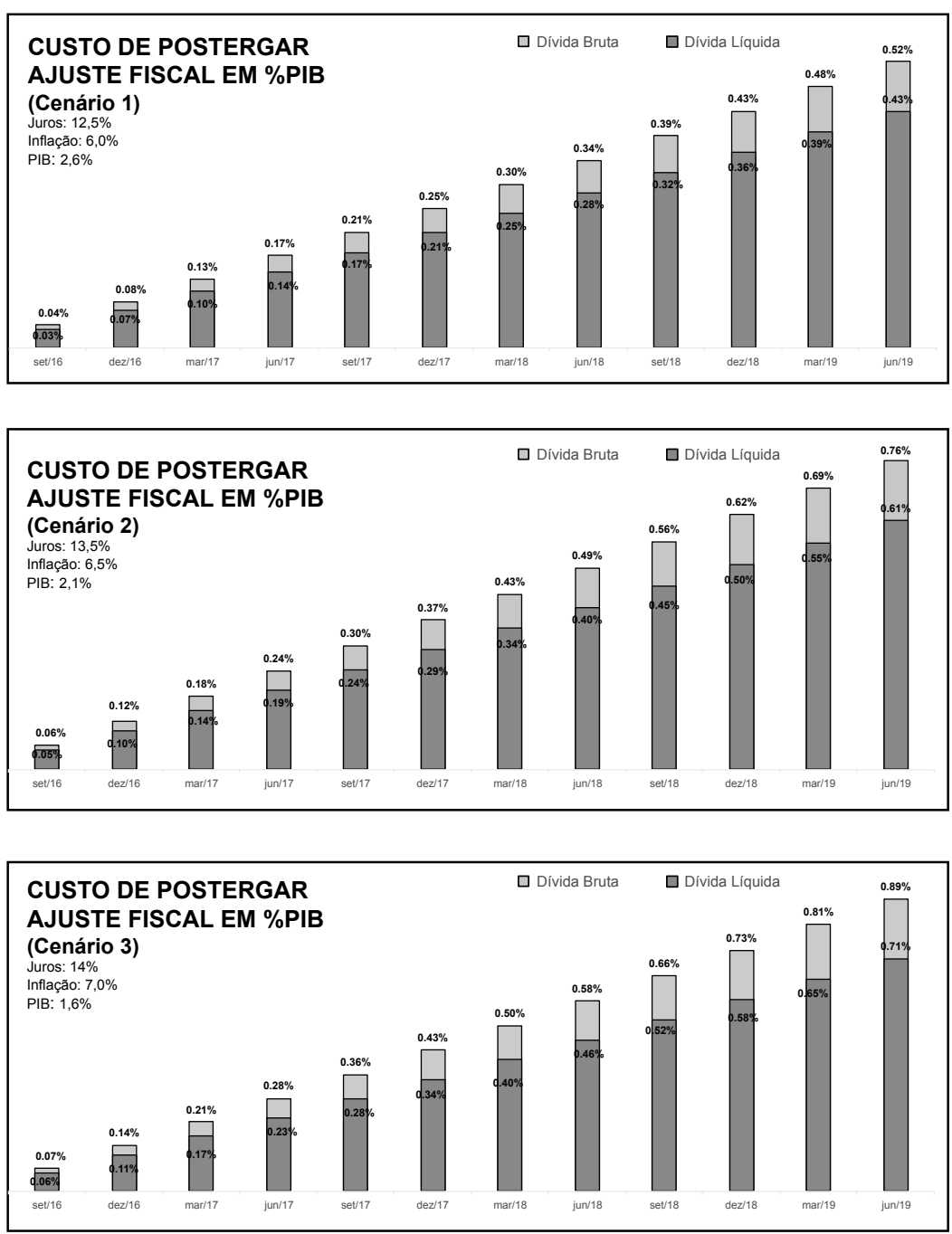


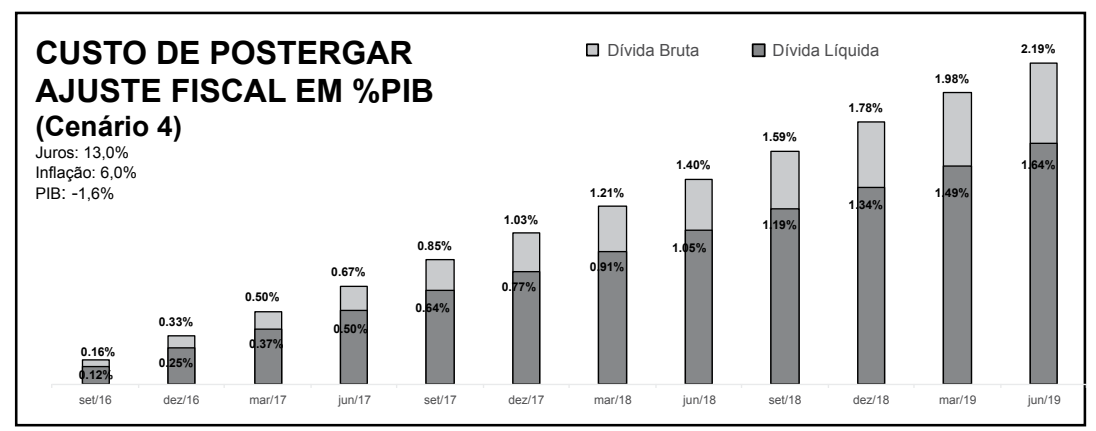

\section{CONCLUSÕES}

Na situação atual do Brasil, a relação entre a dívida pública e o PIB se eleva não apenas devido à forte diferença positiva entre o juro real e o crescimento do produto, mas também devido a um superávit primário fortemente negativo. Isto posto, o ajuste necessário para trazer a relação dívida/PIB a uma condição de sustentabilidade se torna cada dia mais difícil, em função do forte crescimento da dívida e do elevado valor do juro real.

Neste trabalho calculamos, de forma aproximada, as condições de sustentabilidade da dívida e o Custo do Atraso na sua obtenção. Os resultados são apresentados para quatro diferentes cenários e por tipo de dívida, trimestre a trimestre, até o prazo de dois anos e meio contados a partir de junho de 2016. Os gráficos estendem este período a três anos.

De forma geral, os resultados obtidos mostram que há uma necessidade urgente de se reverter a trajetória atual da razão dívida/PIB, através de uma redução do déficit primário. Isto vale tanto quando se toma por base a dívida líquida quanto a dívida bruta.

\section{REFERÊNCIAS BIBLIOGRÁFICAS}

Banco Central do Brasil (2016). Série histórica da Dívida líquida e bruta do governo geral. Banco Central do Brasil (2016). Sistema Gerenciador de Séries Temporais (Código:4189).

Blanchard, Olivier; (1990). "Suggestions for a new set of fiscal indicators.” Working Paper $\mathrm{n}^{\circ} 79$, OECD. Blanchard, Olivier; Chouraqui, Jean-Claude; Hagemann, Robert; Sartor, Nicola (1990). "The sustainability of fiscal policy: New answers to an old question”. OECD Economic Studies $n^{\circ} 20$. IBRE, FGV. Monitor do PIB IBGE (2016). Séries Históricas. Tesouro Nacional (2016). Várias publicações. 